\title{
Integration of Laser Scanning and Imagery for Photorealistic 3D Architectural Documentation
}

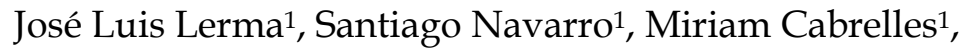 \\ Ana Elena Seguí1, Naif Haddad ${ }^{2}$ and Talal Akasheh ${ }^{3}$ \\ ${ }^{1}$ Universidad Politécnica de Valencia \\ ${ }^{2}$ Hashemite University \\ ${ }^{3}$ Cultech for Archaeology and Conservation \\ ${ }^{1}$ Spain \\ 2,3 Jordan
}

\section{Introduction}

Documentation of architectural and archaeological sites and monuments is an activity that requires the capture of information from different sources. Metric information is mandatory as the basis for documentation, information management, archiving, analysis, monitoring and dissemination activities, among others. In highly weathered environments, accurate 3D models are required for multi-temporal analysis over time in $4 \mathrm{D}$, altogether with imagery. Experience has shown that it is possible to provide the necessary information with the required accuracy and completeness only by integration of multisource data (Georgopoulos \& Ioannidis, 2006). Especially in large and complex monuments parallel use of geodetic and surveying measurements, photogrammetric data acquisition with imagery and terrestrial laser scans has proven to be the ideal combination (Haddad, 2007; Haddad \& Ishakat, 2007). Furthermore, the multi-sensor integration of surveying data (not only terrestrial but also aerial) and architectural needs should be combined with a multi-resolution approach, spanning from few centimetres down to millimetres, if necessary, both in geometry and in texture (Guidi et al., 2008; Remondino et al., 2009). A general overview of the typical requirements and solutions for cultural heritage documentation based on purpose, product, methodology or eventual emphasis is presented in Patias (2006).

Modern technology has changed matters in documentation radically and promises to keep bringing rapid changes. Photographic and non-photographic (graphic) documentation tools are merging in one process, in which the digital photographic technology is the main base (Haddad, 2010; Haddad \& Akasheh, 2005). Until the wide spread used of terrestrial laser scanning (TLS) for cultural heritage documentation, most of the multi-temporal information for documentation and conservation activities was based mainly on graphic documentation: 2D drawings of elevation plans, cross-section and last but not least, images (analogue or digital). However, photographs are easier to interpret and recognize than drawings; they contain information about surface detail and can provide information on the condition of a monument, before, during, and after restoration. Nowadays, the afore-mentioned documents are still requested by architects or building personnel but the analysis is starting 
to be fully in 3D owing to: first, the simplified and comprehensive data acquisition of data sets in 3D mainly by terrestrial laser scanners and 3D cameras; second, availability of easyto-use software that handles millions of features such as points, point splats, meshes and textures fully in 3D; third, availability of surveying equipment all over the world either image-based, range-based or satellite-based.

It is well-known that the input data (points with intensity and/or colour values) coming from TLS after registration has a limited impact on architectural and archaeological documentation in contrast to the widespread used of photographs (Fig. 1). In fact, the field of conservation has very slowly assimilated the advancements of technology (Eppich \& Chabbi, 2006). The techniques range from simple hand-drawn sketches to sophisticated virtual reality representations. The point clouds are generally used for visualisation purposes in 3D, dissemination and extant surveys (Fig. 2). Out of the point clouds is possible to deliver, on the one hand, position and linear measurements, top and elevation plans, cross-sections and fly-through animations, on the other, efficient and accurate way to record and reconstruct digitally large-scale cultural heritage monuments and sites (Takase et al., 2003).

Despite the time consuming processing and required user's interaction, 3D models are preferred for automating the processing of delivering not only a large number of crosssections but contours and volumetric deformations in the three dimensions. 3D models are also required to analyse thoroughly structural damage assessment (Olsen et al., 2010), deformation on surfaces (Schueremans \& Van Genechten, 2009), alterations on materials and

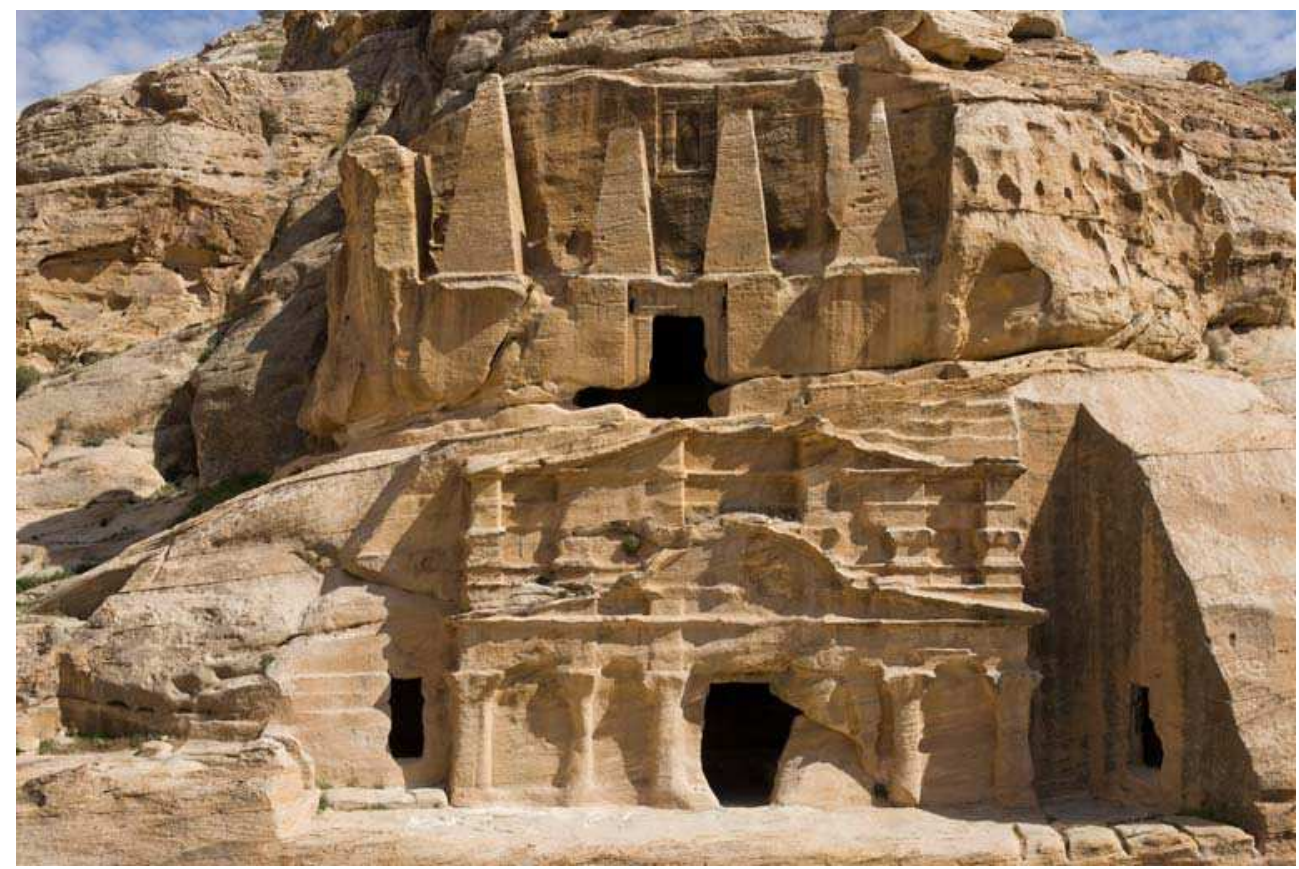

Fig. 1. View of the Obelisk Tomb (upper storey) and the Bab As-Siq Triclinium (lower storey) in Petra/Jordan. 


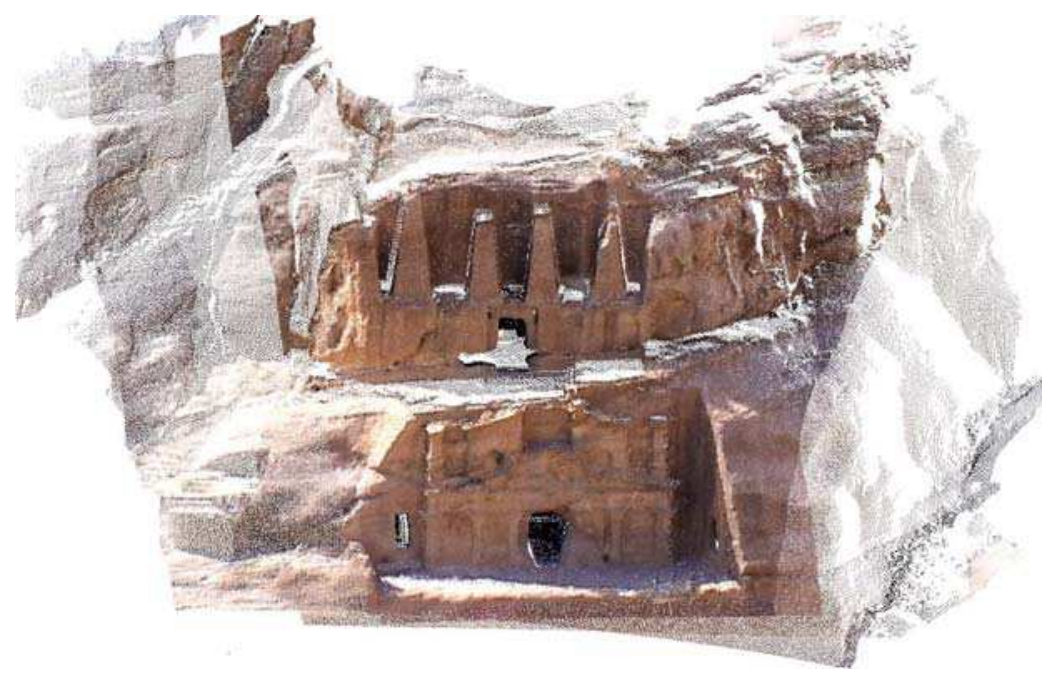

Fig. 2. 3D view of the four point clouds collected for the Obelisk Tomb and the Bab As-Siq Triclinium in Petra/Jordan.

decay mapping either standalone with topographic survey (Rüther et al., 2009) or in combination with image-based sensors such as visible non-metric cameras (Navarro et al., 2009) and thermal cameras (Cabrelles et al., 2009), mainly on large and inaccessible parts of the monuments. Fig. 3 displays four perspective views of one 3D model in which is possible to identify the effects of weathering on architectural features and elements such as cornice, arches, columns and obelisks.

The direction of the light helps to interpret the deteriorations on the surface of the stone monuments due to the concavities of the own high resolution 3D model (Fig. 3). Nevertheless, the incorporation of the texture onto the 3D model increases the ability of visualisation and understanding of the 3D models (cf. Fig. 3 vs Fig. 4). Texture can be acquired by the laser scanner itself (most of the present laser scanning systems support internal or attached digital cameras) or by the user with an external high resolution camera. High quality texture mapping frequently requires external draping of imagery onto the 3D model. With external photography, the user can select the most appropriate position and attitude to take the pictures, the appropriate exposures, and, last but not least, the model of the camera that fits best for the project on purpose. Definitely, the selected camera might not have the same features as the camera integrated in the TLS. Furthermore, there is neither restriction to take pictures with high-end cameras nor metric ones. The user might make use of compact off-the-shelf digital cameras, SLR cameras, high speed camera systems for scientific applications, etc. It is recommended to take pictures with a good camera body and lens to improve the quality of the photorealistic 3D modelling.

This chapter presents the integration of terrestrial laser scanning (TLS) and imagery to generate effectively high quality photorealistic 3D models. This integration is one of the most effective solutions existing nowadays to deliver metric products with high level of appearance (Georgopoulos \& Ioannidis, 2006; Remondino et al., 2009; Lerma et al., 2010b). The TLS provides the 3D information which is used to compute eventually the triangulated $3 \mathrm{D}$ meshes of the monument, whereas the photogrammetric processing is used to texture 

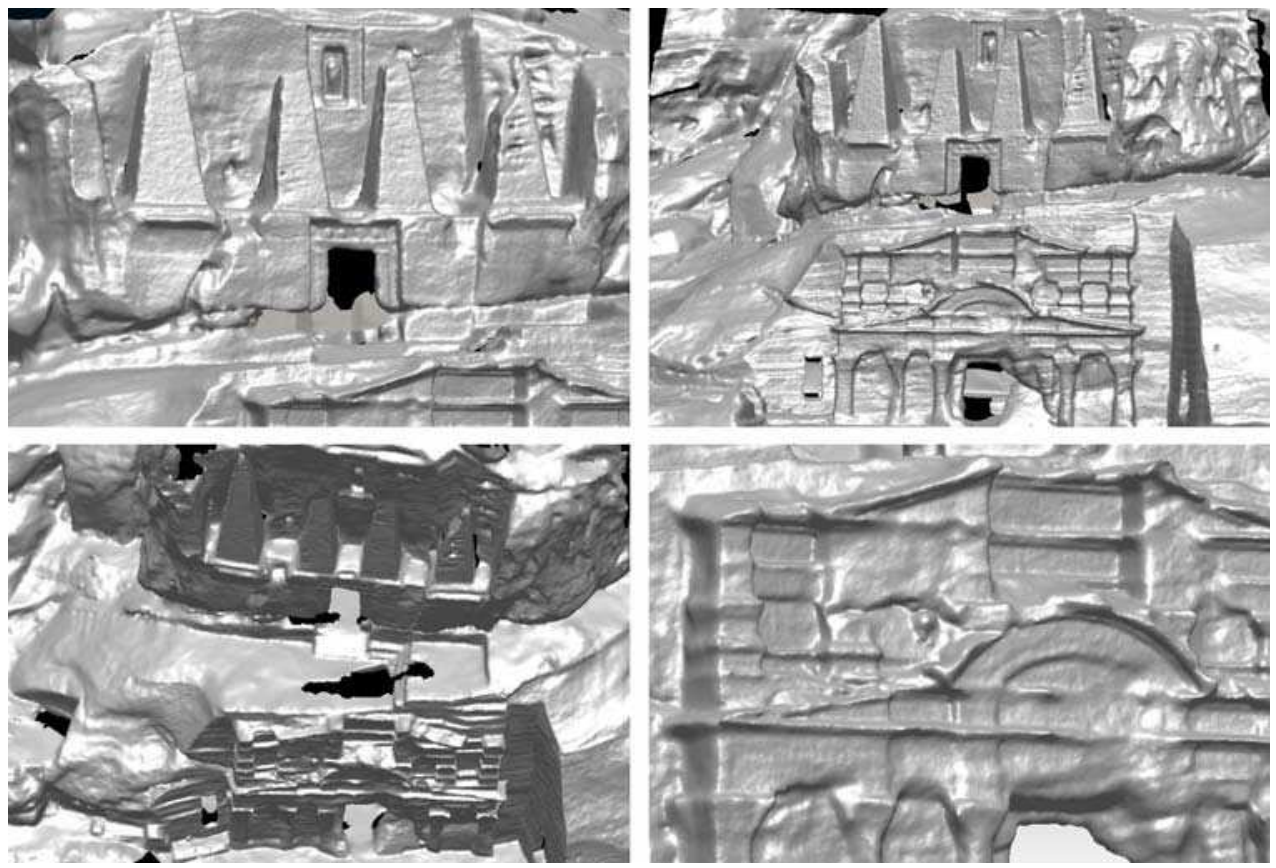

Fig. 3. Perspective views of the Obelisk Tomb and the Bab As-Siq Triclinium 3D model with the lights on: top left) left; top right) right; bottom left) top; and bottom right) Detail of the Triclinium.

accurately the content from the imagery onto the meshes. The approach is suitable to texture either complex architectural monuments such as towerlike tombs (Navarro et al., 2009), high altar and vaults (Biosca et al., 2007) or tiny archaeological engravings at high resolution with close up imagery (Lerma et al., 2010b). Texturing of the virtual monument is based on multiimages to select the best texture map, taking into account occlusions between the object and the set of imagery (Al-kheder et al., 2009).

Other reality-based solutions for 3D modelling of object and sites consider only image-based approaches (Remondino \& El-Hakim, 2006; Cabrelles et al., 2010). The image-based photogrammetric solution can most of the times yield similar results as the integration of the range-based and the image-based approaches, but not always due to texture, light or geometrical conditions. The two kinds of data, image-based and range-based, can be integrated as proposed herein and used at different resolutions for complementary purposes and merged eventually together.

Our approach requires the extraction of point features in contrast to the alternative presented by Alshawabkeh \& Haala (2004), owing to the high probability of success in weathered sandstone monuments. Instead of registering the images to the $3 \mathrm{D}$ model by minimising a photo-consistency cost function (Chetverikov et al., 2007), the well-known collinearity equations are used to relate all the images and the architectural monuments. The performance of the integrated photogrammetric approach presented herein is particularized for complex and highly weathered stone-carved architectural monuments in the Petra Archaeological Park in Jordan, the Obelisk Tomb and the Bab As-Siq Triclinium (Figs. 1-3). 
The remainder of this chapter is structured as follows. Section 2 reviews the architectural documentation mission, specifying the requirements for the surveying, mapping and the modelling. Section 3 describes the context of the monument inside the Petra Archaeological Park, the state of conservation and the weathering effects regarding the Obelisk Tomb and the Bab As-Siq Triclinium. Section 4 is focus on the integration of TLS and photogrammetry, describing our approach for the production of high quality photorealistic 3D models. Section 5 presents the results achieved in the context of architectural documentation and a discussion of the results. Section 6 sums up the presented approach and what is still missing for optimal photorealistic 3D models of today.

\section{Architectural documentation}

Documentation is one of the principal ways available to give meaning, understanding, definition and recognition of the values of the cultural heritage. The importance of documentation may be undertaken as an aid to various treatment activities including: protection, restoration, conservation, preservation, identification, monitoring, interpretation, management of historic buildings and sites and cultural landscapes (Haddad \& Akasheh, 2005; Haddad, 2007), in addition to creating a register of stolen movable objects. However, documentation is not only needed for proper conservation and preservation, but foremost to raise public awareness.

It is a fact that each documentation method has its own advantages and disadvantages. The method which should be applied in each case depends on various factors: cost and time, location facts, size extent of task (content as well as quantitative), accuracy class, kind of approach (preferable non-destructive), and style of results for presentation, interpretation and monitoring. In the photographic methods, the entire vicinity is quasi completely determined, point by point, and the filtration for the extraction of the essential points happens later, meanwhile a relevant difference arises in the acquisition process in situ, compared to a laboratory process. This concept is completely different from the graphic documentation process, where the in situ needs more time (Haddad, 2007; Haddad, 2010). However, a shadow always causes errors in the results, because certain picture information is lost.

A digital orthoimage allows users to point out and manage information about many elements on the documented architectural monument on different layers which is a very important issue in architectural conservation and preservation, for example architectural elements, shape relationships, construction techniques, texture of materials, historical phases, colour values, decorative elements and decay conditions (Agosto et al., 2005; Artesea et al., 2005). In architectural surveys of historical buildings using digital photogrammetry and TLS methodologies, the support of different specific skills is often required; hence it is crucial to choose the correct tools for a multidisciplinary analysis. Actually, architectural documentation is dependent on the instruments used (degree of reliability and precision), representation methods (flexibility degree and amount of information), research approaches (degree of exportability, interdisciplinary nature and transformation), and means of communication (degree of compatibility with other technologies and ability to diffuse) (Bornaz \& Dequal, 2004; Artesea et al., 2005). In fact, when dealing with architectural documentation as in our case, it is important to represent materials, colours, decorations, physical and chemical decay and other phenomena. 


\section{The obelisk tomb and the Bab As-Siq Triclinium in Petra}

Petra is in zone 36 North in the WGS 1984 UTM coordinate system. It forms a plateau (around $850 \mathrm{~m}$ above sea level) surrounded by higher mountains, the Sharah Mountain range, characterized by limestone deposits. At about $900-950 \mathrm{~m}$ elevation, Ordovician sandstone with its white colour and high porosity is found abundantly. The Precambrian sandstone can be found at a lower elevation and forming the largest geologic deposit in Petra. It is characterized by its beautiful multi-coloured mineralogical formations. After walking down the Petra Archaeological Park predominates a wide streambed called the Outer Siq. Most of the important monuments were carved from the Precambrian rock massif on both sides of the wadi (streambed or valley in Arabic). Ordovician monuments are mostly found in the Outer Siq.

It seems that Petra, the ancient Capital of the Nabataean Kingdom, flourished towards the end of the second century BC, and during the course of the first century BC, while most significant contact was with Ptolemaic Egypt during the first century BC, as reflected in Nabataean architecture. The city is remarkable both for its location and its construction. The Nabataeans were creative builders. From the cliffs they carved great altars, temples, tombs, theatres, and even an entire water collection and distribution system. These rock-cut monuments in the Petra Archaeological Park have substantial dimensions which are unique in antiquity. The architecture of Petra constitutes a main source of evidence, not only for the city, but also for the architecture of the late Hellenistic and Roman period. It stimulates a new speculation and evolution of the roughly studied Eastern Hellenistic architecture, which at the very least must be placed, in the much larger context of Hellenistic traditions in the Near East. In fact, during the Roman rule there were changes in patterns in architecture that allowed greater circulation and more freedom of interaction.

Several scholars have noted that the architectural façade formation images of the main monuments of Petra are shared with other Hellenistic and Roman architecture. In fact, the architectural treatments applied at the rock-cut Nabataean façade are maintaining the particularity of the late eastern Hellenistic stylistic architecture. These morphological stylistic elements made Petra a model of a metropolis during the Hellenistic and Roman periods. Actually, Nabataean Petra is the best model to understand the cultural interaction of late Hellenistic stylistic morphology reflected in the Tomb façade formation (Haddad, 1999). The architectural formation of the facades can roughly be divided into two main categories "oriental with Hellenistic doorways" and completely "Hellenistic". However, this means that there is reason to believe that the simpler façade formation, showing stronger oriental influence, would be older than the richly Hellenistic decorated ones such as the AlKhazna. What visitors can see in most of the Nabataean rock-cut façade formation in Petra are some of the best preserved samples of the late Hellenistic morphology often in an appealing combination of oriental stylistic elements (Egyptian cavetto or the Assyrian crow steps and Western stylistic Pedimental doorways). Indeed, through the variety and richness of the decorative architectural elements of the façades (Zayadine, 1987), the Nabatean architects adopting the architectural conception of Hellenization, moved among different cultures create high artistic standards in architecture in cooperation with local tradition materials and landscape (Haddad, 1995; Haddad, 1999). This synthesis with these architectural elements is unique in the History of architecture, and is clear in the significant architectural treatment of the façade formation of the Obelisk Tomb and the Bab As-Siq Triclinium (1st century BC-1st century AD). 
The architectural complex of the Obelisk Tomb and the Bab As-Siq Triclinium (Figs. 1-3) is the first major monument encountered when entering Wadi Musa on the way to the $1.2 \mathrm{~km}$ long Siq, the main gorge entrance to the ancient city of Petra, facing NW and dominating the left side of the road, a few meters down from a complex of three Djin blocks. In reality, the Obelisk Tomb is separated into two monuments, stacked on top of each other: the Obelisk Tomb (upper storey); and the Bab as-Siq Triclinium (lower storey), Fig 1. The Obelisk Tomb (also known as 'Nefesh' Tomb) is named after the four obelisks (approximately $7 \mathrm{~m}$ height) that decorate the top of the entrance of the tomb guarding the rock-hewn cave tomb entrance and was used for burials. The lower storey, the Bab as-Siq Triclinium is decorated in a more classical style and was apparently used for funeral banquets as many such chambers in Petra were used for memorial feasts in honor of the dead, a practice that was also common among the Greek and Romans. This rock-cut architectural connection between the Obelisk Tomb and the Bab As-Siq Triclinium is unique in tomb architecture of Petra.

The Obelisk Tomb houses the graves. The interior space consists of an approximately square chamber $(5.80 \mathrm{~m} \times 5.90 \mathrm{~m}, \mathrm{~h} .4 \mathrm{~m})$ with aboard recess in the back wall in a form of rectangular arcosolium $(2.90 \mathrm{~m} \times 1.70 \mathrm{~m}, \mathrm{~h} .3 .10 \mathrm{~m})$, with two loculi (each one is approximately $2.50 \mathrm{~m} \times 1.25 \mathrm{~m}, \mathrm{~h} .2 .30 \mathrm{~m}$ ), carved in each side of the wall. The façade wall has a slightly raised band on both sides of the doorway and two splayed windows which emerge as slits on either side of the entrance doorway (Fig1). The doorway width is about $1.35 \mathrm{~m}$ and is approached by four steps; each one is $0.40 \mathrm{~m}$ in width.

The lower storey (Bab as-Siq triclinium) is approached by stairs on the left. Generally the façade is highly weathered. The interior space is approximately a square room $(6.45 \mathrm{~m} \times 7.40$ $\mathrm{m}, \mathrm{h}$. 4.35), with benches on three sides. The left and the right sides-walls are plain; meanwhile the back wall has two loculi high up starting $2 \mathrm{~m}$ above the bench top. The triclinium façade (w. $15.60 \mathrm{~m}, \mathrm{~h} .11 .20 \mathrm{~m}$ ), is more in the classical Nabataean style. It consists of an engaged order with six semi-columns and a broken pediment framing a segmental pediment and an upper dwarf order with a broken pediment as characteristic features of the so called Baroque style (McKenzie, 1990). The doorway pillars have anta-type capitals while the entablature has a Doric frieze.

This Nabataean architectural style mixed the Hellenistic visual conception with purely pharaonic features (Obelisks). Here the Nabataean architectural style is an interaction of two different architectural traditions; scenes in which Egyptian and Greek themes create a new dialogue and were juxtaposed in a duality or "double style" at the same façade, that consciously attempted to respect the uniqueness, integrity, and artistic heritage of each architectural tradition. Actualy, these two different historical architectural treatments at the same monument were not only decorative but they indicate how this family wanted to be seen for the eternity. The complex façades are conceived as an independent stylistic screen set in the front of the structure rather than organic and logical elements of the structure as a whole (Haddad, 1999).

Actually, the architecture of the rock-cut façades in Petra represents the final artistic model of the evolution of late Hellenized stylistic morphology (Haddad, 1999; Haddad \& Ishakat, 2007). However, according to the architectural concept of the Eastern Hellenistic architecture, especially the luxury architecture of eastern late Hellenistic palaces reflected in the architecture of Nabataean Petra and the Roman wall painting of the so - called "second Pompeian style" must not only be considered and understood as an actual representation of the free standing models, but as a model of cultural interaction between the East and West and the architectural treatments of the Obelisk Tomb and the Bab As-Siq Triclinium consist of a model of this approach. 


\section{Geometric and appearance modelling by integration of laser scanning and photogrammetry}

This section describes the methodology followed to deliver the high-resolution photorealistic 3D models on large and complex monuments. The general frame of the integration of the range-based and image-based data acquisition and processing is presented in Fig. 4 as part of the architectural documentation. The geometric and appearance modelling by integration of laser scanning and photogrammetry is focus on achieving both the required geometrical accuracy and maximum reliability in the texture mapping.

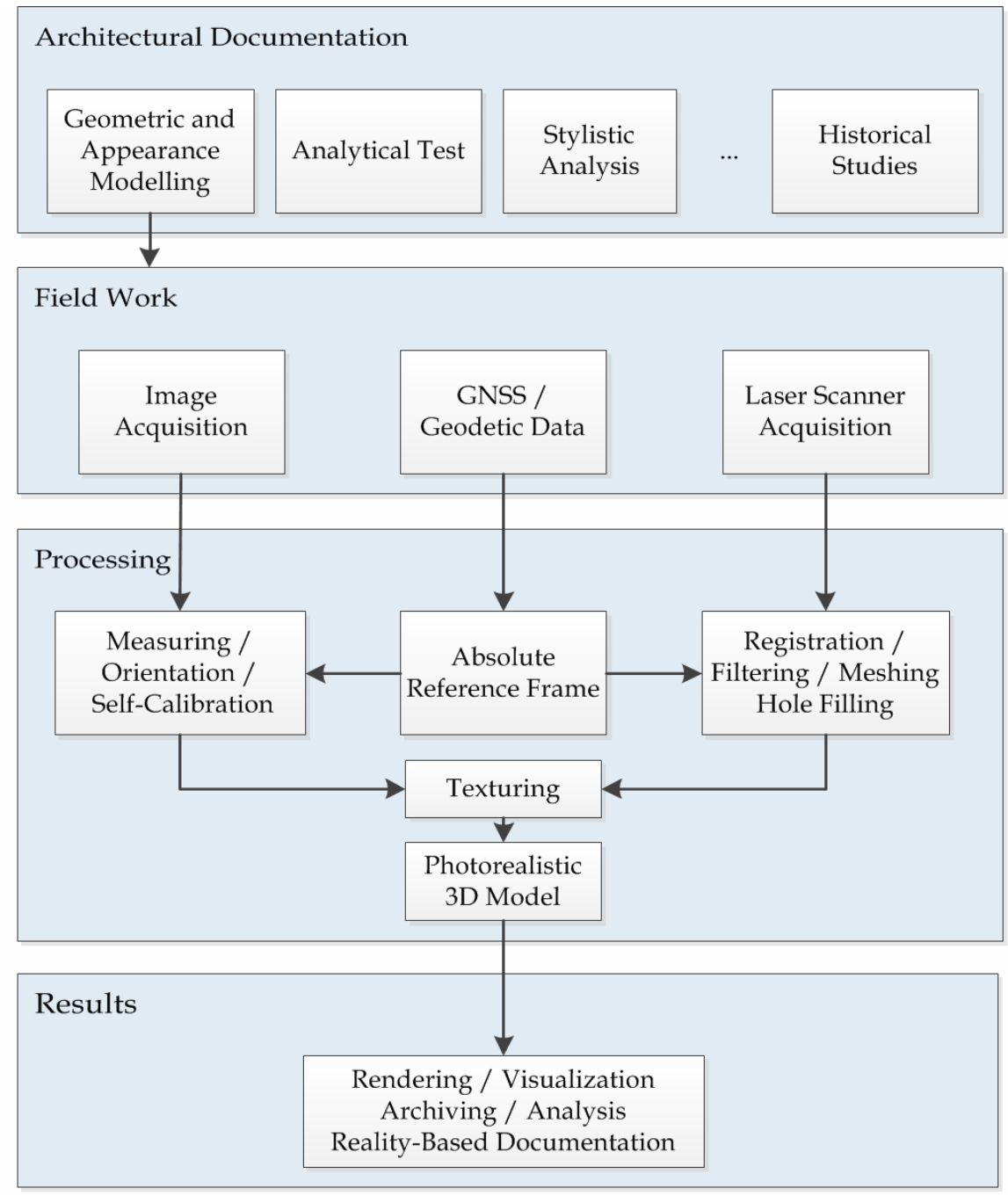

Fig. 4. General pipeline to deliver photorealistic 3D models from image sensors, laser scanners and geodetic instruments 
The pipeline described in Fig. 4 focus the attention on two main activities: on the one hand, field work using different data acquisition systems or sensors, such as GNSS, laser scanner and cameras, opened to either terrestrial or aerial acquisition; on the other hand, parallel processing of the data coming from the different sensors. Each data acquisition system requires typical adjustments. The photogrammetric measurement of the image features previous to the orientation and calibration of the bundle block of imagery can start independently of the laser scanning processing and the geodetic computations, and vice versa. The laser scanning follows a typical workflow: noise reduction, registration, filtering, meshing, hole filling and smoothing, among others. Nevertheless, processing converges towards the end. In particular, after handling the geodetic data (mainly the GNSS network), the Cartesian coordinates of the control points are used to set up the local or official reference frame of the mapping, depending on the country and on the project. Moreover, texturing of the multiple images is carried out onto the 3D model to yield eventually the photorealistic 3D model. After the photorealistic 3D model, different activities and analysis can follow within the own architectural documentation mission such as metric reports and plots, stone surface monitoring, analysis and effects of damages. Out of the previous mission, there are applications that can be conducted best with the photorealistic 3D models, for instance, production of high definition movies, virtual reconstructions, interactive museums, or just print-outs for dissemination activities.

The photogrammetric approach presented herein combines the 3D models (developed from the laser scanning data) and the multiple high resolution external images to yield photorealistic 3D models with subpixel accuracy in image space (Lerma et al., 2010b). The approach consists of two steps which will be developed next:

1. Orientation and calibration of the bundle of images onto the laser scanner datasets.

2. ZI-Buffer for assigning the right texture mapping onto the DSM, after analysing occlusions and double-projections.

\subsection{Orientation and calibration of the bundle of images onto the laser scanner datasets}

The bunch of images used to texture the model has to be accurately positioned and oriented in the object space. This is a geometric requirement that needs to be satisfied to guarantee reality-based modelling from imagery. This step is conventionally achieved by means of the exterior orientation of the image, which relates the coordinates of an object point with the image coordinates of the image point through the perspective centre. The mathematical relationship between the image and object space reference system is set by the well-known collinearity equations (Slama, 1980; Kraus, 1993; Wolf \& Dewitt, 2000; Mikhail et al. 2001).

When the camera is non-metric or uncalibrated, the interior orientation parameters of the camera have to be determined. A review of the different approaches to adjust the different set of additional parameters can be found in (Fraser, 1997; Gruen \& Huang, 2001; Lerma, 2002). For close range applications with non-metric digital cameras, self-calibration bundle adjustment is the most satisfactory approach.

The strategy used to determine the exterior orientation parameters is presented in Lerma et al. (2010a), without adding baseline distance constraints. It can be summarize in the following steps (Fig. 5):

1. Manual, semi-automatic or automatic measurement of homologous image features.

2. Determination of the fundamental matrix of pairs of imagery 
3. Relative orientation of image pairs and block initialization

4. Bundle block adjustment

5. Self-calibration bundle block adjustment

The determination of the blunders in the first and second step is considered crucial to compute quickly the different sets of orientation parameters. Although it is possible to take into account different sets of additional parameters for each image, it is recommended to fix the focus of the camera in order to simplify the self-calibration bundle block adjustment.

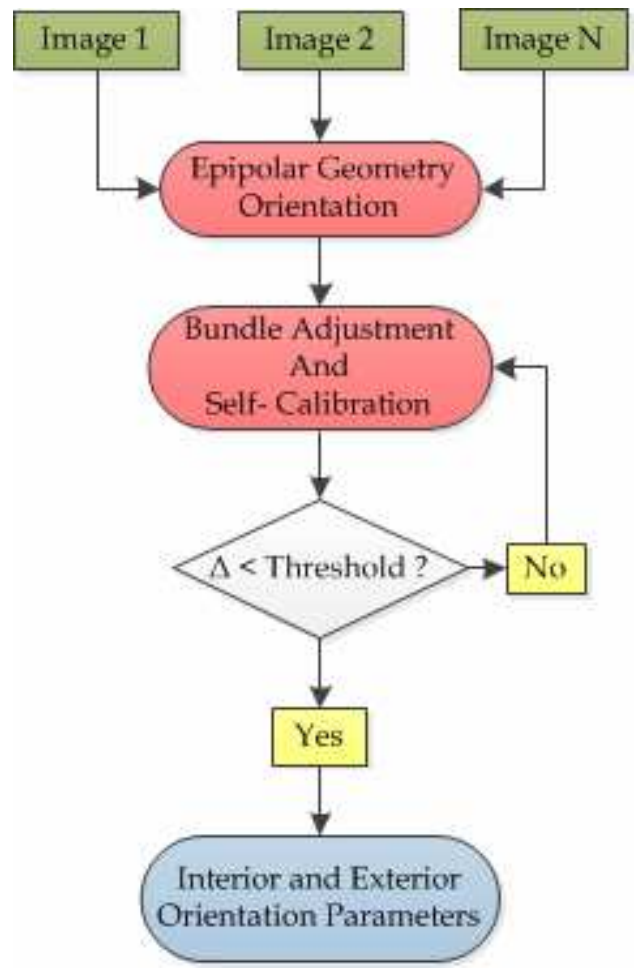

Fig. 5. Multi-image orientation strategy

The delta threshold $(\Delta)$ included in Fig. 5 means that the solution is iterative till all the requirements in the computation of the orientation parameters are satisfied. On the contrary, checking the precision of the different adjusted parameters is crucial to determine eventually high accuracy in the adjustment. Image residuals should be below or around one pixel to consider that the adjustment is correct, despite it not only depends on those values but in the geometry of the bundle of images, the geometry of the monument and the distribution of the image features to compute the afore-mentioned five steps.

The absolute reference frame established by the ground control points (GCPs) can be used at the beginning of the approach, in the middle or at the end. The classical way is to carry out the self-calibration bundle adjustment in the absolute reference frame at the beginning of the photogrammetric processing. It is recommended that the GCPs used in the self-calibration bundle adjustment be the same as those used for the transformation of the unified point 
cloud from the laser scanner onto the absolute reference system. As the number of GCPs usually is smaller than the number of required object points for the registration of the 2D images onto either the 3D point cloud or the 3D model, manual registration is unfortunately the common way required to perform a successful match between the range-based and the image-based datasets. This concept is also known in the literature as co-registration or fusion of 2D and 3D data sets. Nevertheless, it is possible to find in the research community some interesting approaches to automate the identification of 2D and 3D data (Forkuo \& King, 2004, González-Aguilera et al., 2009). Unfortunately, the automatic transfer of homologous features is neither implemented in conventional software nor reliable enough although the future is promising. As stated in Remondino et al. (2009), this is the bottleneck of the texturing phase and it is still an interactive procedure.

\subsection{Texturing from multiple images onto the 3D model}

Texturing of single images onto the 3D model is commonly used in the photogrammetric and the computer vision communities. For the former, mainly to build up 2D products such as image rectifications (that correct the perspective), orthoimages and image mosaics; for the latter, to build up quick and fast texture mapping, most of the times requiring virtual-based appearance instead of reality-based appearance.

It is understood that a snapshot of a high quality photorealistic 3D model should be equivalent to a picture taken from the same camera position and attitude. Biosca et al. (2007) present a comparative study of texture mapping in 3D between conventional laser scanning software and the photogrammetric approach. The output textured 3D models coming from conventional software can not be considered of high quality compared to the presented photogrammetric approach. A summary of our implemented strategy is displayed in Fig. 6 . A particularization of the texturing approach to build up high-resolution photorealistic 3D models in archaeological caves can be found in Lerma et al. (2010b).

The texturing of the multiple images is carried out onto one final 3D model obtained from the point clouds acquired by the TLS, image by image. The ZI-buffer strategy described by Amhar et al. (1998) is used to test the visible faces from the 3D mesh. From each image there is one output textured $3 \mathrm{D}$ model that will be eventually merged to deliver the final photorealistic 3D model. For that purpose, an additional best face perspective check is implemented considering different weights based on the normal angle and on the distance camera model.

\section{Results and discussion}

The results presented in this chapter were acquired basically with three kinds of instruments: first, a non-metric digital SLR camera Canon 1Ds Mark III which provides a maximum resolution of 5616x3744 pixels and fixed lens of $50 \mathrm{~mm}$ principal distance (Fig. 7 displays the four images used for texturing); second, a panoramic midrange time-offlight terrestrial laser scanning Mensi GS 100 from which four point clouds were scanned at a resolution of $5 \mathrm{~mm}$ (one scan) and $10 \mathrm{~mm}$ (three scans), Fig. 2; third a Leica reflectorless total station from which 12 GCPs were measured following a pattern of three rows. All the measurements, the photogrammetric adjustments and the algorithms for texture mapping in 3D were performed with our in-house FotoGIFLE software developed by the first four authors at the Universidad Politécnica de Valencia. The final results are depicted in Fig. 8. 


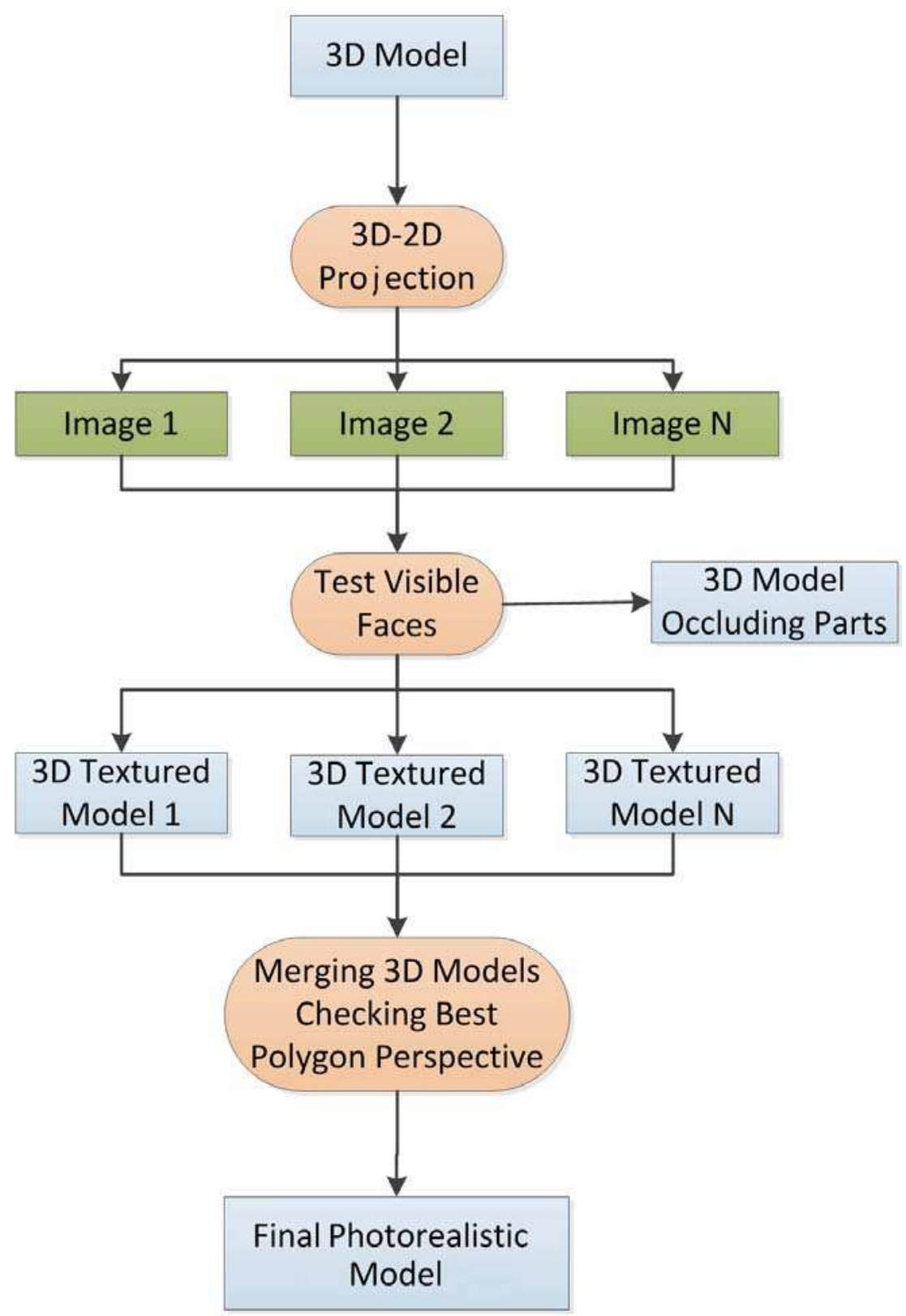

Fig. 6. Workflow used to build up photorealistic 3D models from multiple 2D images 

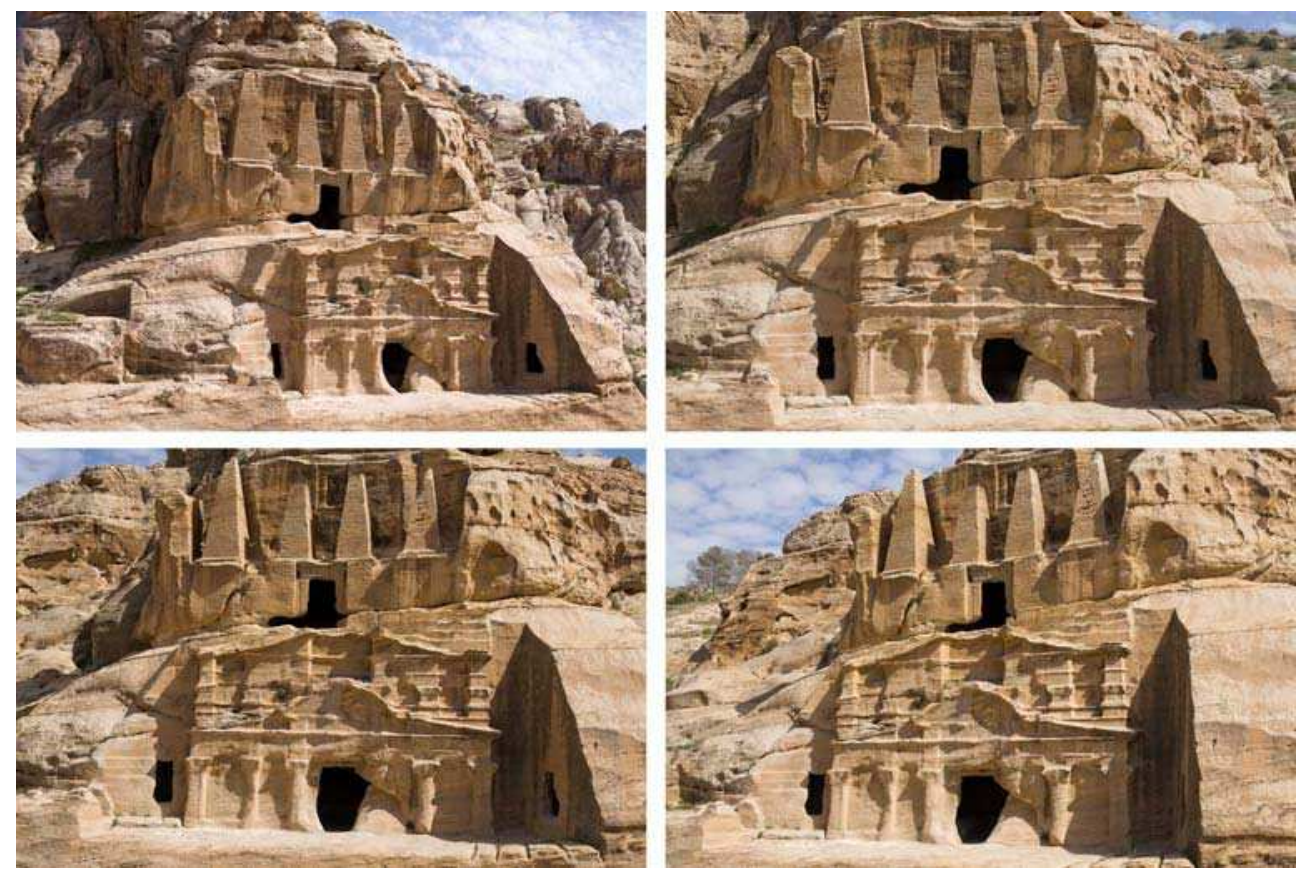

Fig. 7. Set of images used for the photorealistic 3D model of the Obelisk Tomb and the Bab As-Siq Triclinium in Petra

The production of high quality photorealistic 3D models of large and complex monuments and sites is not free of issues such as data management, accessibility, emplacement and, last but not least, money. The results shown in Fig. 8 are mainly for the exterior façade without considering indoors and the upper side of the monument. For the top, additional equipment should have been considered such as the employment of unmanned aerial vehicles (UAVs), but due to economic restrictions that solution was not estimated.

Full data collection of these monuments with terrestrial laser scanning is not advisable. The best way to deliver fully covered indoor and outdoor high quality photorealistic 3D models, with different resolution levels (multi-resolution) depending on the requirements of the project, is integrating both image-based and range-based data, as stated in Forkuo \& King (2004), Georgopoulos \& Ioannidis (2006), Alshawabkeh, Y. \& Haala, N., (2004), and Remondino et al. (2009). Nevertheless, our approach presented herein is valid whether the user extracts the metric information from the laser scanning or from the digital cameras.

Besides, the integration of different sensors and techniques requires that most of the steps be automated. It is preferable to have fully automatic solutions than semi-automatic, and better semi-automatic solutions than manual. The expertise of the user when matching homologous features either in 2D (for images standalone) or in 2D-3D (for images and point clouds or for images and meshes) can be ideally replaced in perfect scenarios; however, it is difficult to accomplish in real projects. Further research is advisable to succeed in everyday, 
everywhere projects with smaller, faster and lighter laser scanners and modern off-the-shelf digital cameras.
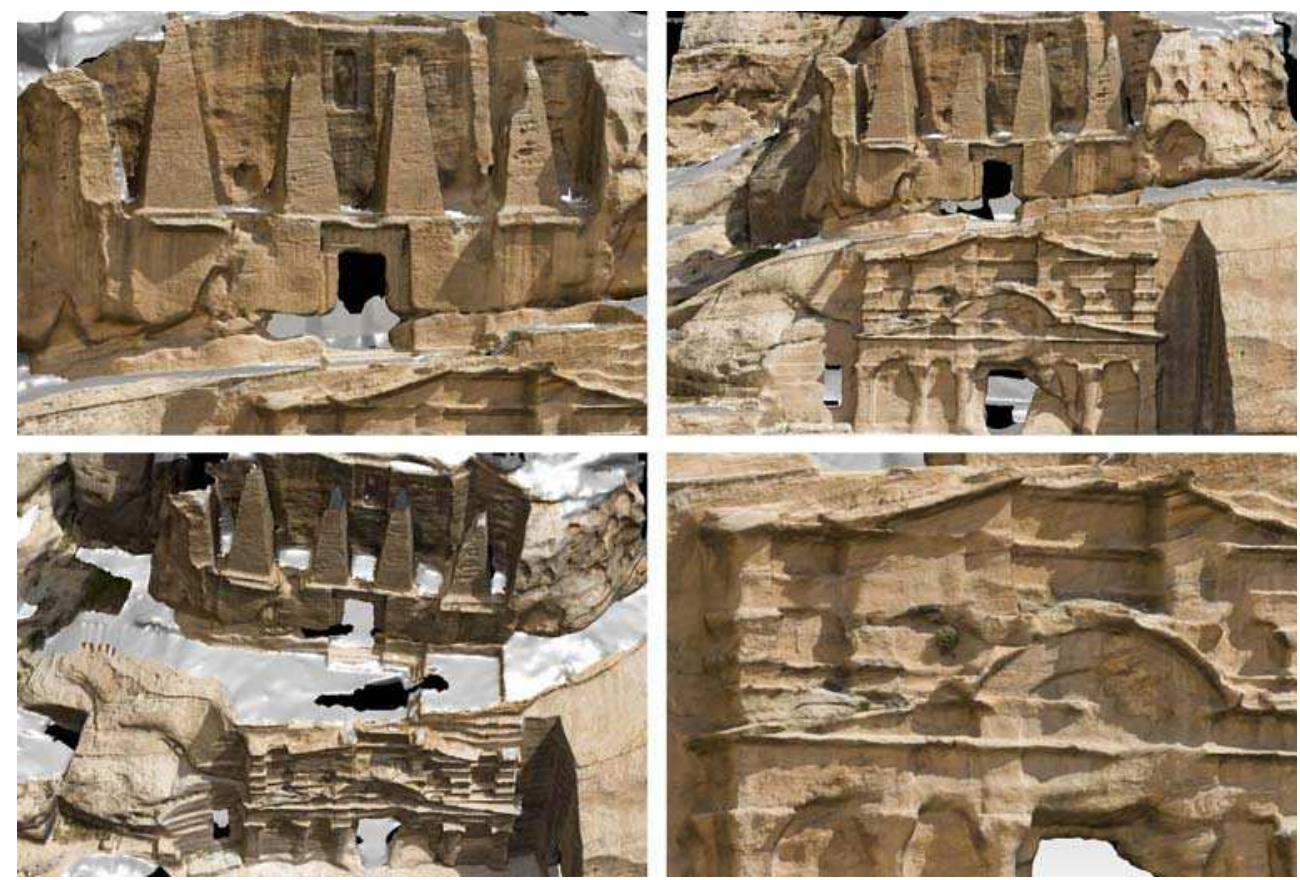

Fig. 8. Perspective views of the Obelisk Tomb and the Bab As-Siq Triclinium photorealistic 3D model seen from different points of view: top left) left; top right) right; bottom left) top; and bottom right) Detail of the Triclinium.

\section{Conclusions and future research}

This chapter has presented a successful approach for photorealistic 3D modelling of cultural heritage by integrating laser scanning technology and photogrammetry. The approach combines the 3D models (developed from the range-based data) and the multiple high resolution external images to yield photorealistic 3D models. The subpixel accuracy in the 2D-3D co-registration process between the images and the model is fundamental to match accurately the texture from the imagery onto the final 3D model without distortion.

The presented approach is not only suitable for yielding high quality perspective views and photorealistic 3D models but amazing reality-based movies (highly appreciated by managers, conservators and restorers of cultural heritage).

Today, the benefit of adding texture with low-cost digital cameras compared to the highcost of terrestrial laser scanners is paramount. Future research should be focus on automating the matching between homologous features either in 2D for imagery, in 
2D-3D for imagery and the model or even in 2D-4D and 3D-4D mainly for monitoring applications.

\section{Acknowledgements}

Authors would like to thank the support provided by the Agencia Española de Cooperación Internacional para el Desarrollo (AECID) to the project A/025999/09, and the Spanish Ministry of Science and Innovation project HAR2010-18620. Additional support to the Jordanian team from Società Italiana per Condotte d'Acqua S.p.A. is very much appreciated.

\section{References}

Agosto, E.; Ardissone, P. \& Bornaz, L. (2005). The castle of Graines: different survey methodologies for the documentation of historical buildings. The International Archives of the Photogrammetry, Remote Sensing and Spatial Information Sciences, 36, 5/C34, (October 2005) 55-58, ISSN 1682-1750

Al-kheder, S.; Al-shawabkeh, Y. \& Haala, N. (2009). Developing a documentation system for desert palaces in Jordan using 3D laser scanning and digital photogrammetry. Journal of Archaeological Science, 36, 2, (February 2009) 537-546, ISSN 0305-4403

Alshawabkeh, Y. \& Haala, N. (2004). Integration of Digital Photogrammetry and Laser Scanning For Heritage Documentation. The International Archives of the Photogrammetry, Remote Sensing and Spatial Information Sciences, 35, B5, (July 2004) 424-429, ISSN 1682-1777

Amhar, F.; Jansa, J. \& Ries, C. (1998). The generation of true orthophotos using a 3D building model in conjunction with a conventional MDT. The International Archives of the Photogrammetry, Remote Sensing and Spatial Information Sciences, 32, 4, (September 1998) 16-22, ISSN 1682-1750

Artesea, G.; Achillib, V.; Boattob, G.; Fabrisb, M.; Salemib, G. \& Trecrocia, A. (2005). Peter Bernini in Calabria: The sculptures of the "Ss. Pietro E Paolo church" in Morano Calabro. The International Archives of the Photogrammetry, Remote Sensing and Spatial Information Sciences, 36, 5/C34, (October 2005), 91-94, ISSN 1682-1750

Biosca, J. M.; Navarro, S. \& Lerma, J. L. (2007). Modelado tridimensional de una bóveda barroca mediante la combinación de láser escáner y fotogrametría, Proceedings of the 7 Setmana Geomàtica, pp. 1-9, Barcelona, Spain , February 2007

Bornaz, L. \& Dequal, S. (2004). The solid image: an easy and complete way to describe 3D objects. The International Archives of the Photogrammetry, Remote Sensing and Spatial Information Sciences, 35, B5, (July 2004), 432-437, ISSN 1682-1777

Cabrelles, M.; Galcerá, S.; Navarro, S.; Lerma, J. L.; Akasheh, T. \& Haddad, N. (2009). Integration of $3 \mathrm{D}$ laser scanning, photogrammetry and thermography to record architectural monuments. The CIPA International Archives for Documentation of Cultural Heritage, 22, (October 2009) 1-6, ISSN 2076-7730

Cabrelles, M.; Seguí, A. E.; Navarro, S.; Galcerá, S; Portalés, C. \& Lerma, J. L. (2010). 3D Photorealistic Modelling of Stone Monuments by Dense Image Matching. The International Archives of the Photogrammetry, Remote Sensing and Spatial Information Sciences, 38, 5, (June 2010) 121-124, ISSN 1682-1777 
Chetverikov, D.; Jankó, Z; Lomonosov, E. \& Ekárt, A. (2007). Creating Photorealistic Models by Data Fusion with Genetic Algorithms, In: Studies in Fuzziness and Soft Computing, Mike Nachtegael, Dietrich Van der Weken, Etienne Kerre, Wilfried Philips (Ed.), 239-263, Springer, ISBN 10.1007/978-3-540-38233-1_9, Berlin

Eppich \& Chabbi, 2006. Recording and Documenting Cultural Heritage - 3D Modeling for Conservation in Developing Regions, In: Recording, Modeling and Visualization of Cultural Heritage, Emmanuel Baltsavias, Armin Gruen, Luc Van Gool, Maria Pateraki (Ed.), 11-20, Taylor \& Francis Group, ISBN 041539208 X, London

Forkuo, E. K. \& King, B. (2004). Automatic Fusion of Photogrammetric Imagery and Laser Scanner Point Clouds. The International Archives of the Photogrammetry, Remote Sensing and Spatial Information Sciences, 35, B4, (July 2004) 921-926, ISSN 1682-1777

Fraser, C. S. (1997). Digital Camera Self-Calibration. ISPRS Journal of Photogrammetry and Remote Sensing, 52, 4, (August 1997) 149-159, ISSN 0924-2716

Georgopoulos, A. \& Ioannidis, C. (2006). 3D visualization by integration of multisource data for monument geometric recording, In: Recording, Modeling and Visualization of Cultural Heritage, Emmanuel Baltsavias, Armin Gruen, Luc Van Gool, Maria Pateraki (Ed.), 375-384, Taylor \& Francis Group, ISBN 041539208 X, London

González-Aguilera, D.; Rodríguez-Gonzálvez, P. \& Gómez-Lahoz J. (2009). An automatic procedure for co-registration of terrestrial laser scanners and digital cameras. ISPRS Journal of Photogrammetry and Remote Sensing, 64, 3, (May 2009) 308-316, ISSN 09242716

Gruen, A. \& Huang, T. S. (2001). Calibration and Orientation of Cameras in Computer Vision, Springer, ISBN 3540652833, Berlin

Guidi, G.; Remondino, F.; Russo, M.; Menna, F. \& Rizzi, A. (2008). 3D Modeling of Large and Complex Site Using Multi-sensor Integration and Multi-resolution Data, Proceedings of the 9th International Symposium on Virtual Reality, Archaeology and Cultural Heritage (VAST), pp. 85-92, ISBN 978-3-905674-14-9, Braga, December 2008, Eurographics Association, Germany

Haddad, N. (1995). Doors and Windows in Hellenistic and Roman Greece, (Dissertation Theses in Greek), AristotileUniveristy of Thessaloniki, Thessaloniki

Haddad, N. (1999). Macedonia, Alexandria, Petra: Tomb Architecture, Proceedings of the International Congress, Alexander the Great: from Macedonia to the Oikoumene, pp. 161171, ISBN 9609054811, Veria, May 1998, Greece

Haddad, N. \& Akasheh, T. (2005). Documentation of Archaeological Sites and Monuments: Ancient Theatres in Jerash. The International Archives of the Photogrammetry, Remote Sensing and Spatial Information Sciences, 36, 5/C34, (October 2005), 350-355, ISSN 1682-1750

Haddad, N. \& Ishakat, F. (2007). 3D Laser Scanner and Reflectorless Total Station: A Comparative Study of the Slots of El-Khazneh at Petra in Jordan. The International Archives of the Photogrammetry, Remote Sensing and Spatial Information Sciences, 36, 5/C53, (October 2007) 356- 361, ISSN 1682-1750

Haddad N. (2007). Towards Creating a Dialogue between the Specialized Technician and non Technician Users of the 3D Laser Scanner. The International Archives of the 
Photogrammetry, Remote Sensing and Spatial Information Sciences, 36, 5/C53, (October 2007) 350-355, ISSN 1682-1750

Haddad, N. (2010). From Ground Surveying to 3D Laser Scanner: A Review of Techniques Used for Spatial Documentation of Historic Sites, Journal of King Saud University [Engineering Science], 2010, (in press)

Kraus, K. (1993). Photogrammety. Fundamentals and Standard Processes, Vol. 1, Dümmler, ISBN 3427786846, Bonn

Lerma, J. L. (2002). Fotogrametría Moderna: Analítica y Digital, Universidad Politécnica de Valencia, ISBN 8497052102, Valencia

Lerma, J. L.; Navarro, S.; Cabrelles, M. \& Seguí, A. E. (2010a). Camera Calibration with Baseline Distance Constraints. The Photogrammetric Record, 25, 130, (June 2010) 140158, ISSN 0031868X

Lerma, J. L.; Navarro, S.; Cabrelles, M. \& Villaverde, V. (2010b). Terrestrial laser scanning and close range photogrammetry for 3D archaeological documentation: the Upper Palaeolithic Cave of Parpalló as a case study. Journal of Archaeological Science, 37, 3, (March 2010) 499-507, ISSN 0305-4403

McKenzie, J. (1990). The Architecture of Petra, Oxford University Press, ISBN 184217164X, United Kingdom

Mikhail, E. M.; Bethel, J. S. \& McGlone, J. C. (2001). Introduction to Modern Photogrammetry, John Wiley \& Sons, ISBN 0471309249, New York

Navarro, S.; Seguí, A. E.; Portalés, C.; Lerma, J. L.; Akasheh, T. \& Haddad, N. (2009). Integration of TLS data and non-metric imagery to improve photo models and recording. A case study on Djin Block No. 9, Petra (Jordan), Proceedings of the 15th International Conference on Virtual Systems and Multimedia, pp. 58-63, ISBN 978-07695-3780-0, Vienna, September 2009, IEEE Computer Society, United Stated of America

Olsen, M. J.; Kuester, F.; Chang, B. J. \& Hutchinson, T. C. (2010). Terrestrial Laser ScanningBased Structural Damage Assessment. Journal of Computing in Civil Engineering, 24, 3, (May/June 2010) 264-272, ISSN 0887-3801

Patias, P. (2006). Cultural Heritage Documentation. International Summer School "Digital Recording and 3D Modeling", Aghios Nikolaos, Crete, Greece, 24-29 April 2006

Remondino, F. \& El-Hakim, S. (2006). Image-based 3D modelling: A review. The Photogrammetric Record, 21, 115, (September 2006) 269-291, ISSN 0031868X

Remondino, F.; Girardi, S.; Rizzi, A. \& Gonzo, L. (2009). 3D Modeling of Complex and Detailed Cultural Heritage Using Multi-resolution Data. Journal on Computing and Cultural Heritage, 2, 1, (July 2009) 1-20, ISSN 1556-4673

Rüther, H.; Chazan, M.; Schroeder, R; Neeser, R; Held, C.; Walker, S. J.; Matmon, A. \& Horwitz, L. K. (2009). Laser scanning for conservation and research of African cultural heritage sites: the case study of Wonderwerk Cave, South Africa. Journal of Archaeological Science, 36, 9, (September 2009) 1847-1856, ISSN 0305-4403

Schueremans, L. \& Van Genechten, B. (2009). The use of 3D-laser scanning in assessing the safety of masonry vaults - A case study on the church of Saint-Jacobs. Optics and Lasers in Engineering, 47, 3-4, (March-April 2009), 329-335, ISSN 01438166 
Slama, C. (1980). Manual of Photogrammetry, Fourth Edition, American Society of Photogrammetry, ISBN 0937294012, Virginia

Takase, Y.; Sasaki, Y.; Nakagawa, M.; Shimizu, M.; Yamada, O.; Izumi, T. \& Shibasaki, R. (2003). Reconstruction with Laser Scanning and 3D Visualization of Roman Monuments and Remains in Tyre, Lebanon. The International Archives of the Photogrammetry, Remote Sensing and Spatial Information Sciences, 34, 5/W12, (July 2003) 325-329, ISSN 1682-1750

Wolf, P. R. \& Dewitt, B. A. (2000). Elements of Photogrammetry with Applications in GIS, Third edition, McGraw-Hill, ISBN 0072924543, New York

Zayadine, F. (1987). Decorative Stucco at Petra and other Hellenistic Sites, In: Studies in the History and Archaeology of Jordan III, Adnan Hadidi (Ed.), 131-142, ISBN 0710213727, Routledge \& Kegan Paul Books Ltd, United Kingdom 


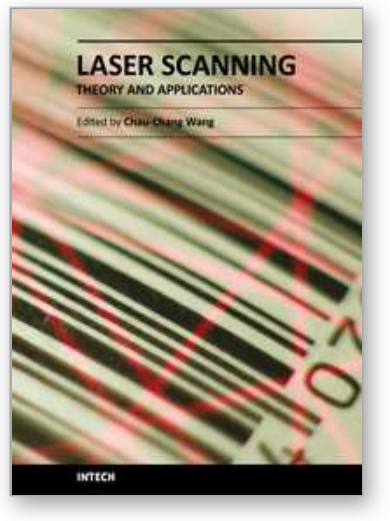

\author{
Laser Scanning, Theory and Applications \\ Edited by Prof. Chau-Chang Wang
}

ISBN 978-953-307-205-0

Hard cover, 566 pages

Publisher InTech

Published online 26, April, 2011

Published in print edition April, 2011

Ever since the invention of laser by Schawlow and Townes in 1958, various innovative ideas of laser-based applications emerge very year. At the same time, scientists and engineers keep on improving laser's power density, size, and cost which patch up the gap between theories and implementations. More importantly, our everyday life is changed and influenced by lasers even though we may not be fully aware of its existence. For example, it is there in cross-continent phone calls, price tag scanning in supermarkets, pointers in the classrooms, printers in the offices, accurate metal cutting in machine shops, etc. In this volume, we focus the recent developments related to laser scanning, a very powerful technique used in features detection and measurement. We invited researchers who do fundamental works in laser scanning theories or apply the principles of laser scanning to tackle problems encountered in medicine, geodesic survey, biology and archaeology. Twenty-eight chapters contributed by authors around the world to constitute this comprehensive book.

\title{
How to reference
}

In order to correctly reference this scholarly work, feel free to copy and paste the following:

José Luis Lerma, Santiago Navarro, Miriam Cabrelles, Ana Elena Seguí, Naif Haddad and Talal Akasheh (2011). Integration of Laser Scanning and Imagery for Photorealistic 3D Architectural Documentation, Laser Scanning, Theory and Applications, Prof. Chau-Chang Wang (Ed.), ISBN: 978-953-307-205-0, InTech, Available from: http://www.intechopen.com/books/laser-scanning-theory-and-applications/integration-of-laserscanning-and-imagery-for-photorealistic-3d-architectural-documentation

\section{INTECH}

open science | open minds

\section{InTech Europe}

University Campus STeP Ri

Slavka Krautzeka 83/A

51000 Rijeka, Croatia

Phone: +385 (51) 770447

Fax: +385 (51) 686166

www.intechopen.com

\section{InTech China}

Unit 405, Office Block, Hotel Equatorial Shanghai

No.65, Yan An Road (West), Shanghai, 200040, China 中国上海市延安西路65号上海国际贵都大饭店办公楼 405 单元

Phone: +86-21-62489820

Fax: +86-21-62489821 
(C) 2011 The Author(s). Licensee IntechOpen. This chapter is distributed under the terms of the Creative Commons Attribution-NonCommercialShareAlike-3.0 License, which permits use, distribution and reproduction for non-commercial purposes, provided the original is properly cited and derivative works building on this content are distributed under the same license. 